\title{
Health Promoting Schools: An Update
}

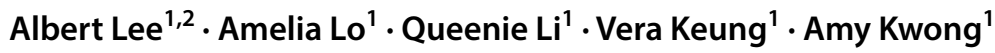

Published online: 15 April 2020

(c) The Author(s) 2020

\begin{abstract}
The concept of a Health Promoting School has been found to be effective to improve health and well-being of students as well as a help with teaching and learning in school. Effective implementation of Health Promoting School is a complex intervention involving multi-factorial and innovative activity in many domains such as curriculum, school environment and community. Many studies evaluating Health Promoting School do not include outcomes reflecting the organisational or structural change as many of those studies are quantitative in nature and the statistical assumptions are not valid reflecting the organisational structure changes. Recent global meetings of experts have reviewed the impact on student health from the perspectives of school environment, school policies on health, action competencies on healthy living and community linkage. The English Wessex Healthy School Award Scheme and the Hong Kong Healthy School Awards Scheme have developed detailed systems to analyse whether each individual school has reached the standard of a model Health Promoting School reflecting a more holistic appreciation and understanding of all the effects of school-based health promotion with positive award-related changes. However, not many schools are able to implement Health Promoting School in its entirety, so cores indicators are needed as a starting point for wider implementation. Hong Kong Healthy School Awards Scheme is still ongoing with data for analysis of indicators with significant correlation with better health and well-being. We identified the core indicators and substantiated the requirements for successful outcomes by supplementing the established award-scheme framework with a review of recent literature and documents. Framework of Health Promoting School would go beyond improvement of health literacy to enable a more efficient system for education and health on children, hence a good investment in children.
\end{abstract}

\section{Key Points for Decision Makers}

This paper highlights:

How a healthy school award scheme would provide a comprehensive framework for development of Health Promoting Schools with core indicators as inputs for implementation.

The details for implementation and the outcome measures for evaluation of Health Promoting School.

Electronic supplementary material The online version of this article (https://doi.org/10.1007/s40258-020-00575-8) contains supplementary material, which is available to authorized users.

Albert Lee

alee@cuhk.edu.hk

1 Centre for Health Education and Health Promotion, The Chinese University of Hong Kong, 4th Floor, Lek Yuen Health Centre, Shatin, New Territory, Hong Kong

2 JC School of Public Health, The Chinese University of Hong Kong, Shatin, Hong Kong

\section{Need for Updating on Health Promoting Schools}

\subsection{Health Promoting School Framework to Tackle Triple Health Burden}

A recent paper on school health has raised the question of what constitutes school health with wide debate depending on geographic location, morbidity and mortality pattern of children and adolescents in the area, existing infrastructure and resources, and culture [1]. Equipping schools with the capacity to tackle the 'Triple Health Burdens': the emergence of 'new' communicable diseases, the epidemics of non-communicable disease (NCD) and the global burden of mental health, should be the fundamental vision and mission of a school. The "Triple Health Burdens" are challenges for both developed and developing countries of the contemporary world. The emergence of 'new' communicable diseases (the unexpected outbreak of severe acute respiratory syndrome [SARS] in 2003 with more than 1800 patients in over a dozen countries worldwide within two months, with clustering of cases in Hong Kong 
and Toronto [2]. The recent COVID-19 with over 1.1 millions confirmed cases globally (82,930 confirmed cases in China, over 600,000 cases in Europe and over 300,000 in America as on 5 April 2020) in over 100 countries within less than 3 months since outbreak in China at the time of writing [3]. This reminds us of the dictum of public health practice, 'prevention better than cure' [2,3]. This is true not only for infectious disease but also for NCD. In 2011, the United Nations adopted 'The Declaration of the Highlevel Meeting of the General Assembly on the Prevention and Control of NCD' [4]. The key action is to reduce risk factors and create health-promoting environments [5]. NCD accounts for one-third of premature deaths [6] so it is important to reduce the risk factors for NCD early. World Health Organization (WHO) published a 'Mental Health Global Action Program' and a 'Movement for Global Mental Health' in 2007 [7]. The disease burden for mental illness is estimated to show that the global burden of mental illness accounts for $32.4 \%$ of years lived with disability (YLDs) and 13.0\% of disability-adjusted lifeyears (DALYs), instead of the earlier estimates suggesting $21.2 \%$ of YLDs and $7.1 \%$ of DALYs [8]. Effective school health intervention should target preventive measures at primary and secondary levels at an early stage. Health Promoting School (HPS) framework can help to build up effective preventive strategies in school setting.

Young people ought to be involved in school and community-based intervention for NCD [9]. Effective school health promotion programs in changing health behaviours are more likely to be complex, multi-factorial and innovative activity in many domains (curriculum, school environment and community) [10,11]. During the eighties, WHO initiated the concept of HPS moving beyond individual behavioural change to consider organizational structure changes for health improvement covering six key areas: healthy school policies, school physical environment, school social environment, action competencies for healthy living, school health care and promotion services, and community link $[12,13]$. Evidence should be gathered extensively about what schools actually do in health promotion using the HPS framework with a detail system of analysis how each individual school has reached the standard of a model HPS [13-17].

\subsection{Healthy School Award Scheme to Establish High Quality Standard of HPS: Hong Kong Experience}

The HPS model has shaped school health promotion in different parts of the world including the low-income countries [18]. The WHO Global Accelerated Action for the Health of Adolescents (AA-HA!) guidance reiterates that "every school should be a health promoting school", and recommends that "Countries that do not have an institutionalised national school health programme should consider establishing one and countries that do have such programme should continuously improve them to ensure that they align with the evidence base on effective interventions and emerging priorities" [19]. The English Wessex Healthy School Award Scheme (WHSA) [15] and the Hong Kong Healthy School Awards Scheme (HKHSA) by Centre for Health Education and Health Promotion of the Chinese University of Hong Kong (CHEP) [16, 17, 20] have developed detailed systems to analyse whether each individual school has reached the standard of a model HPS, reflecting a more holistic appreciation and understanding of all the effects of school based health promotion with positive award-related changes. The schools will undergo evaluation of the performance and status in relation to the six key areas of HPS adapted from the WHO's guidelines to be considered for award. The evaluative process for HKHSA included reviewing the documentations, conducting interviews with teachers, parents and students as well as observation of school physical and social environment. Schools with HKHSA are recognised in the Healthy School Forum and on the CHEP's website.

Data from the pre- and post-surveys of the 962 Primary 4 (P4) students and 1221 Secondary 3 (S3) students in five primary schools and four secondary schools presented to be audited for accreditation of HKHSA after 2 years of implementing the scheme were collected for analysis. Students from the schools which reached certain level of HPS standard as indicated by HKHSA, were compared with students whose schools did not receive the award, and the results showed significant improvement in self-reported health status and academic standings, certain health behaviours as well as satisfaction with life [21]. Primary 4 and Secondary 3 students were chosen to examine the changes for the cumulative impact of HPS at this mid-point of schooling. Another study adopted multi-stage random sampling among schools with awards and those schools not involved in the award scheme nor adopting the concept of HPS (nonHPS). For award group, 5 primary schools and 7 secondary schools were sampled for the study with 510 students and 789 students sampled respectively, and for the 'NonHPS' group, there were 8 primary schools and 7 secondary schools sampled with 676 students and 725 students sampled respectively [22]. Students of the schools with award were found to be better with statistical significance in personal hygiene practice, knowledge on health and hygiene as well as access to health information [22]. Award schools were found to have better school health policy, higher degrees of community participation, and better hygienic environment [22]. CHEP was commissioned by Quality Education Fund of Hong Kong SAR Government to establish the Thematic Network of HPS aiming to sustain the HPS movement in 2010. The pattern of emotional health of students over years was analysed among 1204 primary 4 and 678 secondary 
3 students of 17 primary schools and 5 secondary schools when they first joined the network in 2010. Similarly, to the rationale of previous study [21], students from those grades were chosen. The self-harm behaviours of students had dropped significantly among schools involved in the CHEP thematic network of HPS [23].

There are also numbers of papers analysing the data from the HKHSA as comprehensive system of monitoring and evaluation of performance of HPS [24-28]. Cochrane Review of WHO HPS framework for improving the health and well-being of students and their academic achievement has been conducted [29]. The review was only based on 67 included cluster-randomised controlled trials (RCTs) taken place at the level of school, district or other geographical area. The RCT is not designed for testing organisational or structural change as the statistical assumptions underpinning RCT are not valid reflecting organisational or structural change because of the requirements of RCT such as blinding, randomisation, are needed for drawing statistical inference. Inchley et al. challenged whether HPS initiatives would lead to immediate change at the individual level, so one should study the potential markers of success associated with process [30]. Therefore, updating of HPS through scoping study is needed to identify the indicators of HPS to highlight the ways in which schools have adopted HPS principles successfully under the six key areas: healthy school policies, school physical environment, school social environment, action competencies for healthy living, school health care and promotion services, and community link [12, 13], and the conditions to be in place to flourish. There is also a need to review the evidence of HPS effectiveness on a boarder perspective dealing with complexity of the school system [31] to link education and health $[18,32]$. The following sections report the findings from international forums, review of recent literature, documents and guidelines from international institutions on HPS and child and adolescent health to supplement and substantiate the core indicators and requirements evolved from HKHSA, an established award-scheme framework.

\section{HPS and Better Health of Children and Adolescents: Reviewing Previous Studies/Research from International Consultation Meeting/Forum}

Two global projects, (Global Consultation meeting on Emerging issues in Adolescent Health at Wingspread Conference Centre, USA ["Wingspread Consultation"]) in 2011 organised by Johns Hopkins Bloomberg School of Public Health, and Stellenbosch Institute of Advanced Study on International Health Promoting School (HPS) Colloquium ("Stellenbosch Colloquium") in South Africa in 2011 supported by Peter Wall Institute of Advanced Study of University of British Columbia, Canada); gathered leading scholars on child and adolescent health and HPS to shed further lights on HPS. They shared the recent science on different aspects of child and adolescent health to enlighten the direction of HPS development along the six key areas to improve health of children and adolescents more effectively.

The "Wingspread Consultation" explored the implications of recent research in the fields of epigenetics, adolescent neurodevelopment and neurobiology on adolescent health. Special journal issue reports the science challenging our thinking to place the individual adolescent within the context of both his/her environment, and within a life course perspective [33]. The linkage of policies and programmes to current understanding of science has added new insights on research on young people's health [34]. Adolescent brain is associated with elevated activation of reward-relevant brain regions, and sensitivity to aversive stimuli may be attenuated [35]. Review of current biological models for addiction highlights the interactive influences of genetic and environmental contributions to addictive behaviours of adolescents supporting the evidence of preventive strategies targeting risk factors and enhancing protective factors at individual, familial and community levels [36]. Greater understanding of the epigenetic mechanism being dynamic in responding to both internal and external environmental stimuli has highlighted the new opportunities for development of early prediction and prevention paradigms with early intervention [33]. These new insights have led WHO to prioritise their interventions addressing the common social determinants of health risk behaviours of adolescents and the importance of the balance of action directed towards the policy and regulatory environment influencing individual behaviours [33].

"Stellenbosch Colloquium" was attended by 40 experts from 5 continents to share the global and regional experience surrounding HPS with Stellenbosch Consensus Statement [37]. There is agreement that both health promotion in school setting and HPS can have positive change in the lives of school children and the communities in which they live, and the capacity of HPS to:

- reduce the burden of disease and improve the resilience of individuals and communities

- be transformative for individuals, schools, and communities, enabling and empowering them to attain higher levels of function, and ultimately be stronger citizens with greater capacity for contribution to society

The other key areas of HPS, action competencies for healthy living and school health care and promotion services, need continuous enhancement to sustain those positive changes. Adopting the HPS model requires a change in mindset or a paradigm shift and refinement of educational 
investment and just provision of resources, engagement of non-government organisations (NGOs), or obtaining of international funding. The Consensus Statement has suggested some novel approaches including:

- The opportunities that HPS create may provide common ground for alliance between government departments (particularly health and education), and between various disciplines, professionals and sectors. This "bridging" function may be one of the most powerful influences of successful HPS, and is likely to promote healthier public policy as well as more cost effective, equitable and higher quality collective action to promote wellness

- Accreditation and rewards programmes that define commitment and recognise excellence may encourage schools to expand their health promoting programmes or to become HPS

- Comprehensive evaluation methods are needed to adequately quantify the cost-benefit of health promoting programmes or HPS and their effectiveness.

There are not many accreditation and rewards programmes for recognising excellence in HPS. The WHSA [15] and HKHSA [16, 17, 20] have developed detailed systems to analyse whether each individual school has reached the standard of model HPS, reflecting a more holistic appreciation and understanding of all the effects of school-based health promotion with positive award-related changes. For HKHSA, based on the HPS Performance Indicators (PI) developed by CHEP, evaluation tool including sets of questions related to the PI were developed to assess the HPS status of the school. Stakeholders' survey collected information from all teachers and non-teaching staff, $20 \%$ of all students and their parents. Additionally, the team would observe the school environment on the day of visit to evaluate the physical and social environment of the school. Individual interviews with the teachers and various posts of staff together with group interviews of parents and students were also conducted to retrieve information on the implementation of HPS and the health education and health promotion that had been conducted. WHSA scheme developed a set of indicators with a number of statements or targets relating to each area in which schools performed and the goals to achieve. Status of health education and promotion was assessed, and weaknesses and areas for development within the Award were identified as well as setting targets to be achieved. The tool was sent to schools for completion by a senior teacher and the co-ordinators of Physical Education (PE) and Personal, Social and Health Education (PSHE) [14, 38].

WHSA was developed in the 1990s and HKHSA is still ongoing, and study has recently been conducted to identify core indicators with potential leading to better health and well-being [39]. Taiwan has taken reference from HKHSA to develop an award scheme for accreditation and awards [40]. "Wingspread Consultation" and "Stellenbosch Colloquium" have reinforced the importance of the six key areas of HPS being the main pillars for school health improvement. The existing established framework of HKHSA (Appendix 1) supplemented with review of recent literature and documents on HPS would identify the core requirements under the different key areas [school environment (physical and social), school policies on health, community links, action competencies, school health care and promotion services] to become an effective HPS.

\section{Further Substantiation of Elements for Health Promoting School}

\subsection{Scoping Study}

This update of HPS has taken reference from scoping reviews that are used to present a broad overview of the evidence related to the topic, irrespective of study quality, but useful to examine emerging areas to clarify concepts and identify gap [41, 42]. As explicit guidelines for scoping review are still emerging [41], this study makes use of scoping study which has included literature search and review of recent policies/guidelines/recommendations/reports/ studies and other relevant documents on the current recommendation and implementation of HPS. The authors have already identified 20 indicators having significant impact on health-related outcomes [39], and the scoping study can provide detail standards of those core indicators under the five key areas (not including school health care and promotion services as explained later on) building on HKHSA framework based on WHO standard [11, 43] (Appendix 1). The sources of international documents come from leading global organisations such as WHO, UNESCO, World Bank, ASCD (Association of Superintendents and Curriculum Development) FRESH (Focusing Resource on Effective School Health) partnership and IUHPE (International Union for Health Promotion and Education) either as part of managerial practice or school health programme, were searched and reviewed as part of the scoping study. Literature search was also conducted from November to December 2018 using combination of literature search strategies to collect the research-based evidence, including electronic database queries (Global Health, Medline, PubMed), hand searching of key journals and consultation with experts and stakeholders with the following keywords: Healthy School or Healthy Schools or Health Promoting School or Health Promoting Schools. The grey literature was collected via Google and the leading academic/professional institutions on health promotion. 
The documents included in the review are empirical studies describing health promotion action(s) in school (either managerial practice or school health programme) focused on student health, and based on a whole school approach, which committed to consider making change in HPS (either initiation or further development) and providing explicit information about the outcomes/impacts/opportunities/difficulties of the action(s) on a structural, organisational and/ or individual level. A three-stage selection process has been conducted to screen out the included document for analysis. The selection process comprises:

- review of the title and abstract by two researchers to determine the relevance for review. The document that does not fulfil the inclusion criteria (either not within the scope or insufficient information) will be excluded after reaching a consensus;

- review of the full text of selected documents by two reviewers independently, based on a shared template to ensure internal validity and to further select the documents after discussion; and

- analysis of the remaining documents by the researchers.

Details of the process are included in the PRISMA (Preferred Reporting Items for Systematic Reviews and MetaAnalyses) Flow Diagram (Fig. 1) [44]. As described earlier, literature search was conducted via electronic database queries (Global Health, Medline, PubMed) as well as hand searching of the key journals. A total of 1400 articles were retrieved using these methods. The research team underwent selection process of the papers and documents by their titles and abstracts. There were 183 full-text articles and documents being selected and assessed for eligibility by reviewing the abstracts. After reviewing the full text, reviewers excluded 71 papers that did not fit the criteria, and 112 papers were included. One researcher reviewed all the scientific papers, another reviewed all the selected international documents, and a third researcher reviewed the grey literature. During the review process, the researchers identified elements that would supplement the existing indicators of HKHSA. They categorised those elements and placed them under the related indicators as annotation to substantiate and/or expand the contents under each indicator. Tables 1 , 2, 3, 4 and 5 provide substantive annotation of the different components and the respective elements of the five key areas of HPS. The key area, school health care and promotion services is not included, as this paper aims to focus more on educational investment particularly on bridging functions so school environment (physical and social), school polices on healthy school, community link and action competencies for healthy living are the key areas with greater significant impact. Children tend to learn their patterns of behaviours from the norms and values held by the school environment [45].

\subsection{Findings}

The scoping study provides detail standards of the core indicators (identified in another study [39]) under the five key area building on HKHSA framework based on WHO framework [11, 43].

With regard to Healthy School Policies, it is more applicable to define policy that would influence the behaviour of a manager or managed objects to influence and guide the school's actions in promoting health and wellbeing of its students, staff, family and the wider community [46]. Table 1 shows how the position of health education and health promotion in school can be further substantiated [24, 31, 42, 47-58, 60-64, 84] and factors to be considered in reviewing existing policies related to health on four topics [50, 59, $65,66]$ (healthy eating, safe school, harmonious school and student health care). School health profile should be created to reflect the needs responding to local priorities and the needs of all students, including marginalised children, and it should NOT be limited to narrowly defined health outcomes to be achieved through single health promotion. It should be articulation of the joint vision, mandate and framework for the HPS programme in a written policy to secure leadership and commitment, and should clarify resource allocation with strong and sustained integrated school health programming embedded within Education Sector Development Plan (Table 1). School should move towards "fostering coalescing leadership in combinations of leaders' work together" to include students, and other educational personnel, parents and caregivers as well as outside service providers (Table 1). There should be re-orientation to new public health movement with emphasis on using structures and spaces to stimulate individual health-promoting behaviour, and schools need more-detailed guidelines related to physical structures, e.g. how to address hygienic standards and food safety (Table 1).

Safe and healthy conditions for the life and work of the whole school community can promote better teaching and learning, and also better interpersonal relationship. The school environment should be a place where students are free from danger, disease, physical harm or injury. Table 2 shows how school physical environment can be further enhanced under different elements to be more conducive for health and safety $[13,50,67-70]$. The eating environment should emphasise health in terms of nutrition and hygiene including food safety (Table 2). Children learn their patterns of behaviours either prosocial or antisocial from the norms and values held by the social environment in which they are bonded [45]. The school environment should be a place where all students are free from fear or exploitation, 
Fig. 1 PRISMA flowchart. PRISMA Preferred Reporting Items for Systematic Reviews and Meta-Analyses

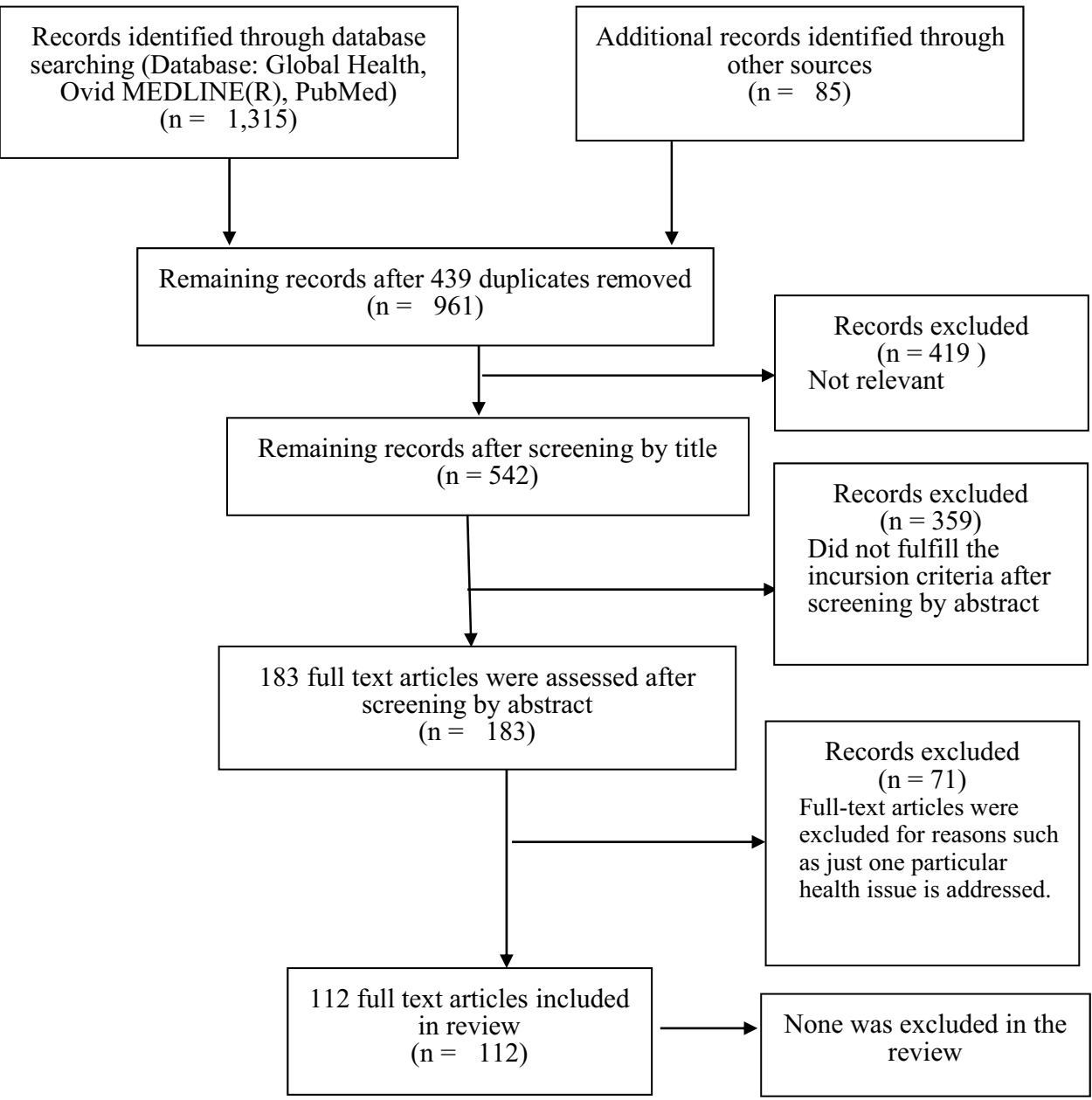

and codes against misconduct exist and are enforced with clear rules and procedures for responding to aggressive acts and ensuring that students, staff and parents are aware of and enforce these rules and procedures (Table 3). Different elements under different components of school social environment can be further substantiated to create the values conducive for desirable social behaviours (Table 3) [49, 50, 53-55, 59, 71-76]. Students should be engaged and empowered in planning and implementing school activities. School needs to cultivate socially supportive relationships giving people a sense of being valued and cared for with reciprocity. This can be promoted through a teaching curriculum and extra curricula activities that place the importance of opportunities for pupils (Table 3 ).

Information can improve people's knowledge about the health consequences of their choices, but there is little evidence that information alone changes behaviour. Enhancement of action competencies on healthy living is needed with a comprehensive health education curriculum to enhance personal health skills and developed strategically with professional development of teachers. Table 4 shows how those perspectives can be further enhanced under different elements [26, 49, 50, 52-54, 56, 57, 59, 68, 69, 76-83]. For example, schools should ensure student participation in programme implementation to enhance their capacity and connectedness to the programme, using diverse learning and teaching strategies to account for different learning styles including and making use of real-life conditions as "life skills education" so students can gain insights into matters related to health (Table 4). The ethos of HPS should be part of the curriculum in teacher training and education to strengthen teachers' understanding of student's participation in class with paradigm shift of delegating school health promotion activities to lay school health counsellors not only relying education or health professionals together with improved system of monitoring and evaluation of health education needs in school setting (Table 4).

Community can synergise and synchronise with school initiatives and intended learning outcomes rather than adopting passive roles and even expressing hesitation. Community members can appreciate a balanced approach recognising the importance of academic and non-academic factors and values of developing social and human capitals to nurture young people. Schools would also develop 
Table 1 Healthy school policies (PO)

Components

1. The position of health education and health promotion in school
Substantiation of elements/indicators

1.1 School formulates a set of comprehensive school health policies based on their own needs It should NOT be limited to narrowly defined health outcomes to be achieved through single health promotion [47]

Preparation of school health profile for needs assessment [48] and more measurable standards of health-promoting schools based on the socio-cultural context of both developing and developed countries [49]

Focus of school change to develop HPS can best be articulated as a mission or vision and wellness is well embedded into the moral purpose [43]

School health-related policies should respond to local priorities and the needs of all students, including marginalized children [50]

1.2 A working group or committee was set up to plan, implement and monitor the school health promotion

School leadership support, staff training and a designated team is needed for HPS24, [25]

Articulate the joint vision, mandate and framework for the HPS programme in a written policy to secure leadership and commitment, and clarify resource allocation [52]

1.3 Health promotion was included in the school working plan and accorded a high priority for allocating resources

Developing both a sense of direction in the goals of the school and clear and unambiguous leadership and administrative support [53, 54]

Policy, practice and resources must support not only academic learning for each child, but also the experiences that encourage development of a whole child who is knowledgeable, healthy and motivated and engaged [55]

Ensuring that funding supports for all six areas of HPS not just focused mainly on morbidity and mortality reduction [56]

Members of the school community need to share a similar vision of what an HPS is and what they want to achieve [57]

To ensure strong and sustained integrated School Health programming embedded within Education Sector Development Plans [58]

The action plan should be developed collaboratively with the staff, maintaining a clear connection to the healthy school standards at the national level [59]

1.4 Related personnel were consulted in the drawing up, implementing and monitoring the school health policy

There should move towards "fostering coalescing leadership in combinations of leaders work together" to include students, and other educational personnel, parents and caregivers as well as outside service providers [31]

Staff should be empowered through "shared ownership" of the change and innovation, and by a programme structure that enables each member to be involved in planning and strategic decision making [27]

Reviewing the education sector's existing models and activities, and demonstrate how the HPS programme is a "win-win" strategy [52]

School led or bottom-up process has been identified as an essential component of successful school-based health promotion initiatives [60-63]

Teachers also spoke of the benefits that they gained and were happy to see themselves as instigators $[31,64]$

2. The existence and review of health policies with related personnel being informed and consulted through effective channels

\subsection{Healthy eating}

The surrounding environment of the school needs to reflect the values being developed in the school, e.g., restricting the sale and advertising of unhealthy products near the school entrance [59]

2.2 Safe school

It should address physical safety issues, such as guidelines to ensure the school has adequate water and sanitation facilities [50]

\subsection{Harmonious school}

It should ensure a safe environment to protect students and staff from abuse, sexual harassment, discrimination and bullying and builds resilience and self-esteem [50]

2.4 Active school

Provision of diversified physical activity opportunities for whole school community, periodic assessment of physical fitness and follow up students with poor fitness or weight management needs (over and under-weight), and physical activities as reward rather than punishment [65]

2.5 Student healthcare

Consultation with stakeholders, especially youth, in setting up school health service, and also intersectoral collaboration in supporting school health services [66] 
deeper understanding of the needs of the community to enable schools acting as agents of change in the lives of students, families and communities. Table 5 shows how different elements under different components of community link can substantiate the effect of linkage with community [49-51, 53, 54, 57, 73, 84, 85, 86]. Strong linkage with community can ensure a consistent approach across the school and between the school, home and wider community, and the knowledge exchanged would enable the communitybased partner to provide a better service to the school and the school benefits from receiving higher quality products (Table 5).

\section{Proposed Key Standards for HPS and Outcome Measures}

Tables 12, 3, 4 and 5 provide detail standards of the core indicators under the five key area building on HKHSA framework (Online Appendix 1). Study by Lee et al. has identified those indicators to have significant impact on health-related outcomes [39] and those core indicators can be good starting point for wider implementation of HPS because not many schools are able to implement in full scale [24, 87]. Table 6 lists 19 core indicators from 5 key areas reflecting the inputs of HPS performance. The outcome measurements of the different indicators can take reference from the Hong Kong Student Health Survey Questionnaire (HKSHQ) [23, 40] measuring the student health-related outcomes. HKSHQ incorporates the US Center for Disease Control and Prevention (CDC) Youth Risk Behavioural Surveillance [88] and WHSA [15] adapted by CHEP [20, 21] with continuous refinement as a tool for assessing student health status/health-related outcomes [23, 89]. K6 scale by Kessler and colleagues [90] has been used to assess emotional disturbance as well as the Life Satisfaction scale by Huebner and colleagues [91] as part of HKSHQ building up the student health profile. Table 6 provides the core indicators as inputs for HPS performance and also the possible outcome measurements. This should serve as a basic framework for HPS standard with outcome measures to evaluate the HPS effectiveness. Apart from providing a framework for holistic approach to improve health literacy [92], HPS can also provide a framework for holistic approach to improve school's organisation and culture.

No detailed scoping study was conducted on the key area, school health care and promotion services and one would take reference from the "Forum for Investing in Young Children Globally" (iYCG) initiated by the Institute of Medicine (now renamed as National Academy of Medicine),

Table 2 School physical environment (PE)

\begin{tabular}{|c|c|}
\hline Components & Elements/indicators \\
\hline 1. Provision of a safe environment & $\begin{array}{l}\text { 1.1 School ensures students' safety whenever students are under their care } \\
\text { Appropriate supervision by properly qualified adults in settings such as pools, playgrounds, and } \\
\text { sporting venues [67] } \\
\text { 1.2 School has a safe design and organize regular checking and maintenance for the school's } \\
\text { building, facilities, amenities and equipment } \\
\text { Be aware of placing a school adjacent to major highways that would, increase the exposure of } \\
\text { school occupants to traffic exhaust, recognized as an airway irritant that likely increases asthma } \\
\text { symptoms [67]. Be aware of contamination of nearby groundwater, particles of rooftop material } \\
\text { or substances from the environment that have accumulated [67] }\end{array}$ \\
\hline 2. Promotion of a hygiene environment & $\begin{array}{l}\text { 2.4 School provides clean and hygienic washrooms with sufficient sanitary facilities for students } \\
\text { and staff } \\
\text { Sufficient water and sanitation facilities are provided and where physical structures (buildings, } \\
\text { courtyards, paths and latrines) are sound, welcoming and secure [50] }\end{array}$ \\
\hline $\begin{array}{l}\text { 3. Provision of a suitable physical environ- } \\
\text { ment to enhance learning }\end{array}$ & $\begin{array}{l}\text { 3.1 School provides an adequate and well-maintained ventilation system } \\
\text { People's perceptions of thermal comfort, principally by three environmental parameters: tempera- } \\
\text { ture, humidity, and air movement. Ideal temperature for classrooms }\left(21^{\circ} \mathrm{C} ; 69.8^{\circ} \mathrm{C}\right) \text { is higher } \\
\text { than for gymnasiums }\end{array}$ \\
\hline 4. Provision of a healthy eating environment & $\begin{array}{l}\text { 4.1 School has a system in place to ensure that all food sold or served in school promote healthy } \\
\text { eating } \\
\text { Nutritionally balanced lunch is provided in school, and low-sugar, low fat, low salt foods in } \\
\text { cafeteria removing seasoning [13] } \\
\text { Healthy menu designed for overweight and obese students [68] } \\
4.2 \text { School provides adequate and hygienic places for students and staff to eat in } \\
\text { Increasing awareness of the importance of good nutrition and quality physical education, preven- } \\
\text { tion of use of harmful substances [69] } \\
\text { Allowing healthy food from a local business to be offered at school may compensate for lack of } \\
\text { kitchen preparation space and food safety [70] }\end{array}$ \\
\hline
\end{tabular}


Table 3 School's Social Environment (SE)

Components Elements

1. Addressing the needs of students and staff

2. Creating an environment of friendliness and care in school

3. Assistance for students and staff with special needs

4. Establishment of an inclusive environment of value and mutual respect
1.1 School promotes the students' self-confidence and appraise the staff performance through positive reinforcement

Creating a climate where there are high expectations of students in their social interactions and educational attainments $[53,54]$

schools with no stressful exams and where notices are kindly given to students for their mistakes [49]

The teaching and administrative workloads of teachers and others involved in health-promoting schools projects should be acknowledged [59]

Students do feel that their teachers should model good interpersonal behaviour, such as respect, calmness and rapport [71]

1.3 School involves students in policy making (NB: Not applicable to special school)

Child participation means that children have the opportunity to express a view, influence decisionmaking and achieve change. It must be integral to every activity, from planning to implementing to evaluating activities at local-, district-, national-level and be practiced by all stakeholders [50]

Denmark's Folkeskole (primary and lower secondary education) Act states: "The school shall prepare the pupils for participation, joint responsibility, rights and duties in a society based on freedom and democracy. The teaching of the school and its daily life must therefore build on intellectual freedom, equality and democracy" [72]

Involving students in school projects and education relates to the ethical obligation to involve participants in decisions on health issues that are centrally related to their own lives [58]. They are much more engaged in school health promotion and teaching if they are allowed to influence and affect decisions in class [59]

1.4 School promotes the development of students' skills in leadership, communication and interpersonal relationship

Reinforcing peer education at schools [74]

Developing personal and social responsibility through school organization [73]

Students described 'treating teachers like friends' and 'sharing their life experiences' and teachers described 'feeling like big brothers'. Research has also shown that students who feel fairly treated by teachers and close to people at school are more likely to succeed: they engage in less health risk behaviours and do better in school [75]

Creating a social environment that supports open and honest relationships within the school community. Ensuring school members, including students, staff and parents, have a sense of ownership in the life of the school $[53-55,57]$

Socially supportive relationships were those that gave people a sense of being valued and cared for and where the exchange of support was reciprocal. The relationships should be supported and promoted through a teaching curriculum and extra curricula activities that placed importance opportunities for pupils [76]

2.1 School has a system for the prevention, and management of unacceptable behaviour in school both among students and encourages staff to set personal examples for cultivating students' positive actions

Negative well-being was associated with many factor including feelings that ranged from boredom to frustration and from irritation to fear, and included experiences of abusive behaviour from both teachers and pupils (such as harassment and bullying). negative feelings experienced by pupils often arose from the pressure exerted upon them, by teachers, to achieve academic success. [76]

Clear rules and procedures responding to aggressive acts and ensuring students, staff and parents aware of and enforce these rules and procedures [50]

3.1 School has a system in place to look after students and staff with emotional needs and/or unexpected traumatic life events

School-based counselling services can help identify and support students during difficult times and prevent school absenteeism and dropout [50]

4.1 School has a system in place to ensure equal opportunities among students and staff and provides channels to let the comments and recommendations made by both parties be expressed and heard

Prevention of health- and gender-related discrimination towards learners and educators [69]

4.2 School encourages students and staff to respect and value each other's individuality and differences amongst cultures, genders, religions, disadvantaged groups and races

Pupils had much to say about school rules, many of which they felt to be drawn up arbitrarily, to be incoherent and illogical, and therefore difficult to under-stand Pupils felt many rules which were enforced punitively [76] 


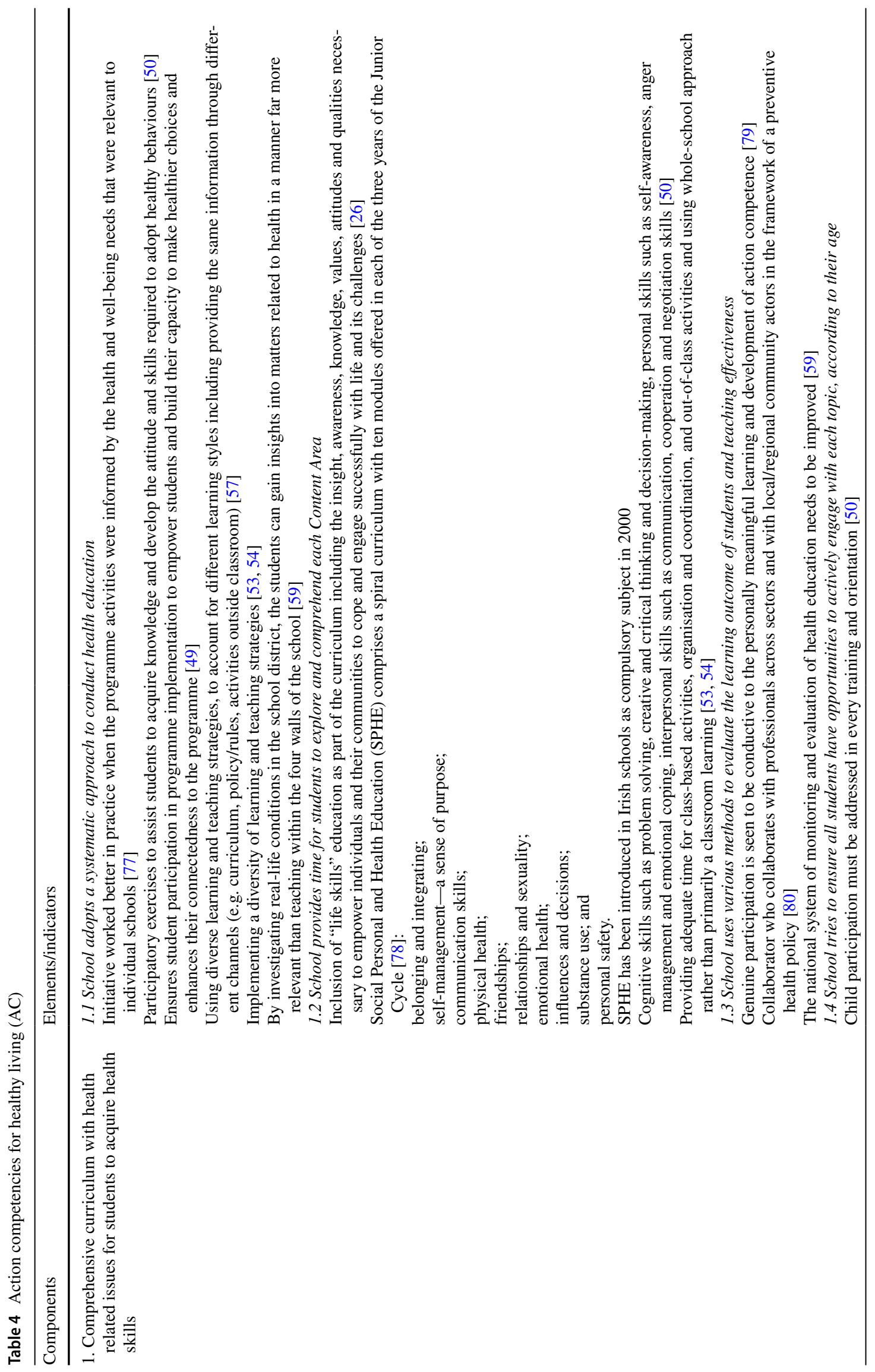




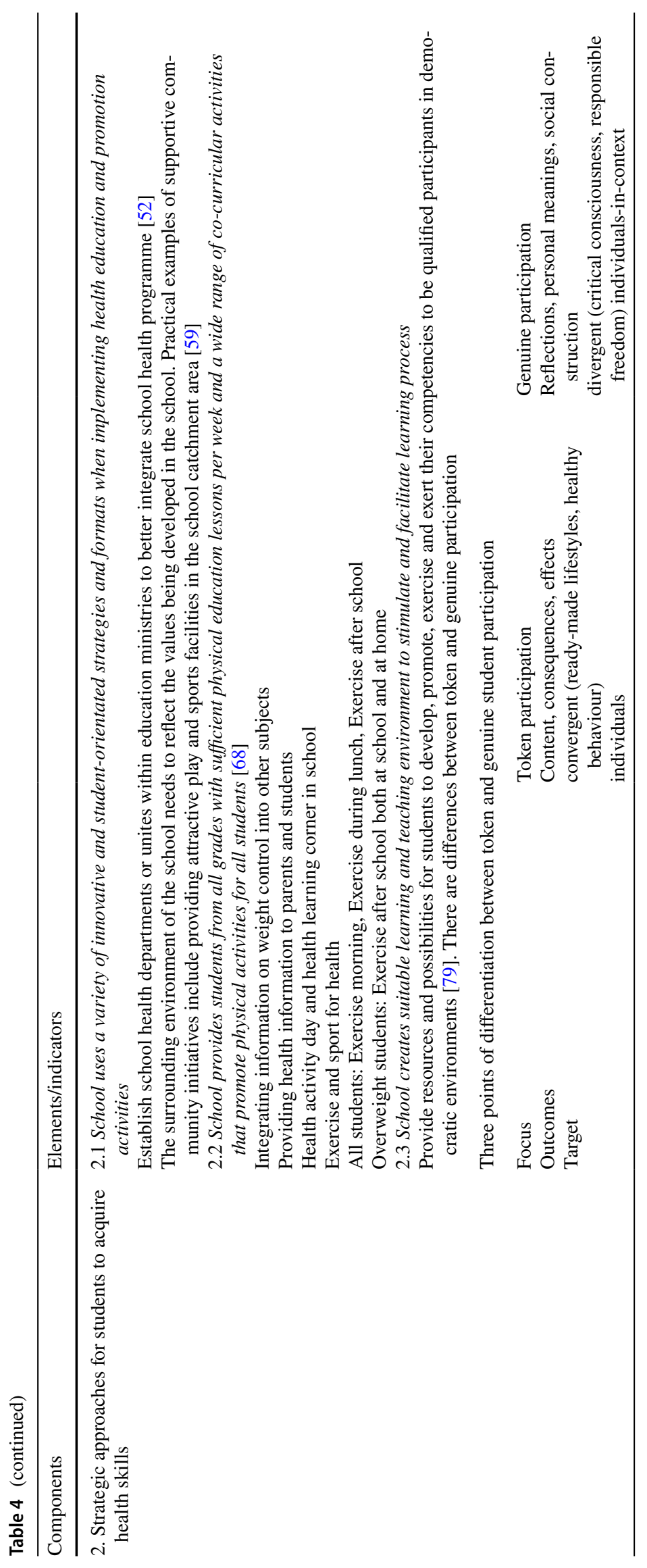




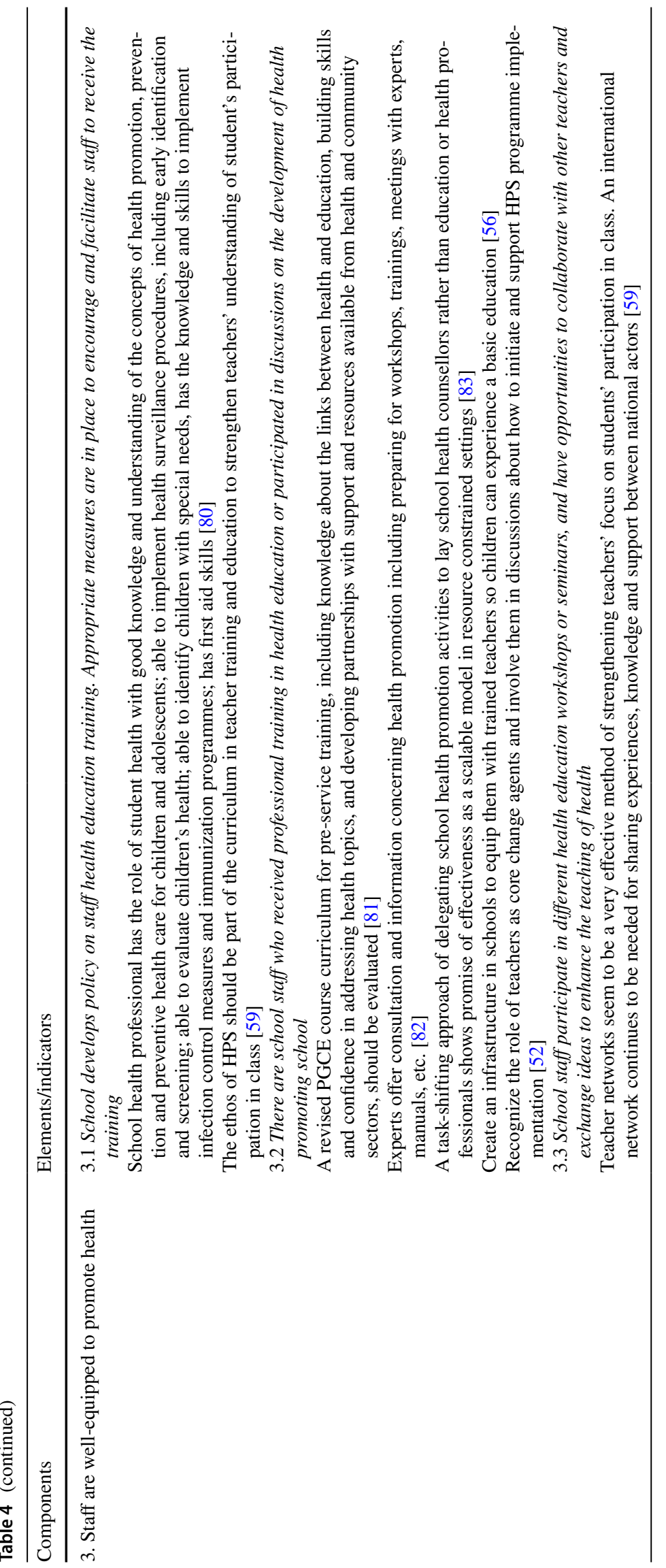


Table 5 Community Links (CL)

Components $\quad$ Elements/indicators

1. Family involvement in school affairs

1.5 School consults parents for recommendations on Healthy School development \& encourages their active participation in the joint discussion on the formulation and review of Healthy School policies

At least one item related to the students' health in the agenda of every PTA council meetings [73]

1.6 School provides opportunities for parents to work closely with the school, including the organisation of, assistance and participation in school and health-related activities

Planning and implementation of briefing sessions about the HPS programme in the scheduled list of the activities for PTA council meetings [73]

Ensuring a consistency of approach across the school and between the school, home and wider community $[53,54]$

1.7 School actively organises health-promoting activities for parents and their family members (NB: Aspects of physical, psychological, social and spiritual health can be considered, including parent education)

Preparing an action plan to integrate health education programmes and the routine parents' education programmes within the participant schools [73]

2. Community involvement in school development 2.4 School actively encourages community members or groups to participate in the joint discussion on the formulation and review of Health School policies

Developing partnerships between the policy makers of both the education and health sector $[50,51]$

2.5 School consults community members or groups that possess substantial understanding of the school for recommendations and/or professional advice on Healthy School development \& involves them in assessing school's developmental needs and/or discussing arrangements for corresponding plans and projects

Qualified health promotion practitioners should be located in schools [84]

Grading of community participation in school activities [85]

Identifying and engaging other individuals or groups outside the school community interested in the process of becoming an HPS can lead to stronger support for the HPS within the broader community [57]

3. Proactive linkage with other community bodies 3.4 School establishes networks with schools and works with them to promote school health promotion

Himmelman methodology describes four degrees of partnering interaction: networking, coordinating, cooperating, and collaborating, with each degree of interaction signifying a different level of partnership between organizations [86]

ASCD Association of Superintendents and Curriculum Development, FRESH M\&E Focusing Resource on Effective School Health-Monitoring and Evaluation, IUHPE International Union for Health Promotion and Education, PTA Parents Teachers Association, UNESCO United Nation Education, Science and Culture Organization, $W H O$ World Health Organization 
Table 6 Proposed key standards of HPS and outcome indicators Source: CHEP 2019 http://www.cuhk.edu.hk/med/hep/hchsc/index.html

\begin{tabular}{ll}
\hline Inputs & Suggested outcomes \\
& $*$ Secondary schools only ** Primary Schools only
\end{tabular}

PO $2.1 * *$ Policy on Healthy eating

PO 2.2** Policy on safe school

PO 2.3* Policy on harmonious school

PO 2.4** Policy on active school

PE 1.1 School ensures students' safety whenever students are under their care

PE 4.1 School has a system in place to ensure that all food sold or served in school promote healthy eating

SE 2.2* School has a system for the prevention, and management of unacceptable behaviour in school both among students and encourages staff to set personal examples for cultivating students' positive actions

\section{SE 3.2}

School has a system in place to look after students and staff with emotional needs and/or unexpected traumatic life events

AC 1.1 School adopts a systematic approach to conduct health education

AC 1.3 School tries to ensure all students have opportunities to actively engage with each topic, according to their age

AC 2.1 School uses a variety of innovative and student-orientated strategies and formats when implementing health education and promotion activities
$\%$ of students having enough fruit every day

$\%$ of students having soft drinks more than 4 time per week

$\%$ of students who are classified as underweight

$\%$ of students that often obey traffic signals

$\%$ of students that often put on seatbelts

Mean Life satisfaction score of students-school experience

$\%$ of students feeling so sad or hopeless that he/she will stop usual activities

Mean Life satisfaction score of students-school experience Mean Life satisfaction score of students-overall life

$\%$ of students having enough physical activity

$\%$ of students having enough physical activity

Mean Life satisfaction score of students-school experience

Mean Life satisfaction score of students-overall life

Mean K6 score of students

$\%$ of students having enough fruit every day

$\%$ of students having soft drinks more than 4 time per week

$\%$ of students think they are having good academic performance in past 12 months

$\%$ of students having enough physical activity

Mean K6 score of students

$\%$ of students having K6 score $>12$

Mean K6 score of students

$\%$ of students having K6 score $>12$

$\%$ of students think they are having good health status over past 30 days

$\%$ of students think they are having good academic performance in past 12 months

$\%$ of students having preserved meat more than 4 times per week

$\% \%$ of students having enough fruit every day

$\%$ of students having candies more than 4 times per week

$\%$ of students having soft drink more than 4 times per week

$\%$ of students having crisps more than 4 times per week

$\%$ of students having enough physical activity

Mean K Score of students

Mean Life satisfaction score of students-themselves**

$\%$ of students think they are having good health status over past 30 days

$\%$ of students that often obey traffic signals*

$\%$ of students that often put on seatbelts*

$\%$ of students having preserved meat more than 4 times per week

$\%$ of students having enough fruit every day

$\%$ of students having candies more than 4 times per week

$\%$ of students having soft drink more than 4 times per week

$\%$ of students having crisps more than 4 times per week

$\%$ of students having enough physical activity

Mean K Score of students

Mean Life satisfaction score of students-overall*

$\%$ of students think they are having good health status over past 30 days

$\%$ of students that often obey traffic signals

Mean Life satisfaction score of students-overall*

Mean Life satisfaction score of students-themselves**

Mean K6 score of students*

$\%$ of students smoke* 
Table 6 (continued)

Inputs
AC $3.2 *$ There are school staff who received professional training in
health education or participated in discussions on the development
of health promoting school

Suggested outcomes

* Secondary schools only ** Primary Schools only

health education or participated in discussions on the development

$\%$ of students think they are having good health status over past 30 days**

$\%$ of students having enough vegetables every day**

$\%$ of students having enough fruit every day**

$\%$ of students having soft drink more than 4 times per week**

$\%$ of students having crisps more than 4 times per week $* *$

$\%$ of students having preserved meat more than 4 times per week**

$\%$ of students having enough physical activity**

$\%$ of students smoke**

Mean K Score of students**

Mean Life satisfaction score of students-living environment**

AC 3.3 School staff participate in different health education workshops or seminars, and have opportunities to collaborate with other teachers and exchange ideas to enhance the teaching of health

$\%$ of students think they are having good health status over past 30 days**

$\%$ of students having enough vegetable every day**

$\%$ of students having enough fruit every day**

$\%$ of students having enough physical activity**

Mean K Score of students**

Mean Life satisfaction score of students-family life**

Mean Life satisfaction score of students-themselves**

Mean Life satisfaction score of students-overall**

AC 4.3 School provides health-related information and resources for family members and the community

$\%$ of students that often obey traffic signals**

$\%$ of students having soft drink more than 4 times per week**

$\%$ of students having enough physical activity**

Mean K Score of students**

Mean Life satisfaction score of students-family life**

Mean Life satisfaction score of students-themselves**

Mean Life satisfaction score of students-friendship**

Mean Life satisfaction score of students-living**

Mean Life satisfaction score of students-overall**

Mean Life satisfaction score of students-family life**

CL 1.2 School consults parents for recommendations on Healthy School development \& encourages their active participation in the joint discussion on the formulation and review of Healthy School policies

Mean Life satisfaction score of students-themselves**

CL 2.2 School consults community members or groups that possess substantial understanding of the school for recommendations and/ or professional advice on Healthy School development \& involves them in assessing school's developmental needs and/or discussing arrangements for corresponding plans and projects

Mean Life satisfaction score of students-family life**

Mean Life satisfaction score of students-themselves**

Mean Life satisfaction score of students-living environment**

Mean Life satisfaction score of students-overall**

$\%$ of students think they are having good health status over past 30 days*

CL 3.2* School links with community bodies and works with them to promote community health education activities

$\%$ of students think they are having good health status over past 30 days**

CL 3.4** School supports staff to participate in various exchange activities in health education

Mean Life satisfaction score of students—school experience*

CHEP Centre for Health Education and Health Promotion, The Chinese University of Hong Kong

USA during the period 2014-2016 [93]. Keynote by Dr Helia Molina, past Minister of Health in Chile described an integrated system in Chile based on an intersectoral public policy on childhood and social protection in one iYCG workshop in 2015 with the theme 'Using existing platforms to integrate and co-ordinate investments for children' [94].

\section{Conclusion}

The scoping study has enriched the contents of the core indicators under the five key areas. There are now more updated details of standards required under each core indicator taking reference from global experience in implementation of HPS (Tables 1, 2, 3, 4, 5 and 6). The findings of this paper 
can provide explicit information on ways to implement HPS under the different key elements (the core indicators) of different key areas, namely school environment (physical and social), school polices on healthy school, community link and action competencies for healthy living. This would enable and empower the school setting to integrate and coordinate a more efficient education, health and social system for healthy child development. HPS is good framework for inter-sectoral approach, and the findings of this paper would provide practical guidance for practitioners to learn how to make a start.

Acknowledgements The authors would like to express sincere thanks to Ceci HY Chan for her assistance in literature search at the early stage of the project. The authors would like to thank Quality Education Fund of Hong Kong Special Administrative Region Government to support the Hong Kong Healthy School Award Scheme and Thematic Network of Health Promoting School.

Authors' contribution Lee is responsible for overall design of the review, reviewing literature to be included, and analysing literature to identify elements substantiating the indicators for HPS, and responsible to summarise all findings in Tables 1,2,3,4 and 5 and developed the key standards of HPS and outcome measures. Lo is responsible for searching documents and grey literature to be included and analysing documents, grey literature and literature. $\mathrm{Li}$ is responsible to search for literature, documents and grey literature, and organization of findings from the analysis. Keung and Kwong are responsible for checking of findings.

\section{Compliance with Ethical Standards}

Funding No funding has been received for preparation of this manuscript.

Conflict of interest The authors want to express sincere thanks to Quality Education Fund of Hong Kong SAR Government for supporting the Hong Kong Healthy School Award and Thematic Network of Health Promoting School. There is no conflict of interests in preparing this manuscript.

Open Access This article is licensed under a Creative Commons Attribution-NonCommercial 4.0 International License, which permits any non-commercial use, sharing, adaptation, distribution and reproduction in any medium or format, as long as you give appropriate credit to the original author(s) and the source, provide a link to the Creative Commons licence, and indicate if changes were made. The images or other third party material in this article are included in the article's Creative Commons licence, unless indicated otherwise in a credit line to the material. If material is not included in the article's Creative Commons licence and your intended use is not permitted by statutory regulation or exceeds the permitted use, you will need to obtain permission directly from the copyright holder.To view a copy of this licence, visit http://creativecommons.org/licenses/by-nc/4.0/.

\section{References}

1. Lee A. School health programs in the Pacific Region. In: McQueen D, editor. Oxford Bibliographies in Public Health. New York:
Oxford University Press; 2018. https://doi.org/10.1093/obo/97801 99756797-0173.

2. Lee A, Cheng FF, Yuen H, Ho M. How would schools step up public health measures to control spread of SARS? J Epidemiol Community Health. 2003;57(12):945-9.

3. WHO. Coronavirus disease 2019 (COVID-19) Situation Report 76. Geneva: WHO. 2020. https://www.who.int/docs/default-sourc e/coronaviruse/situation-reports/20200405-sitrep-76-covid-19. pdf?sfvrsn=6ecf0977_4. Accessed 6 Apr 2020.

4. United Nations General Assembly. Political declaration of the high-level meeting of the general assembly on the prevention and control of non-communicable diseases. New York: United Nations; 2011.

5. Mant D. Principle of Prevention. In: Jones R, Britten N, Culpeper L, et al., editors. Oxford textbook of primary medical care. Oxford: Oxford University Press; 2004.

6. Norheim OF, Jha P, Admasu K, Godal T, Hum RJ, Kruk ME, Gómez-Dantés O, Mathers CD, Pan H, Sepúlveda J, Suraweera W. Avoiding $40 \%$ of the premature deaths in each country, 2010-30: review of national mortality trends to help quantify the UN Sustainable Development Goal for health. Lancet. 2015. https://doi. org/10.1016/S0140-6736(14)61591-9.

7. Patel V, Collins PY, Copeland J, Kakuma R, Katontoka S, Lamichhane J, Naik S, Skeen S. The movement for global mental health. Br J Psychiatry. 2011. https://doi.org/10.1192/bjp.bp.109.07451 8.

8. Vigo D, Thornicroft G, Atun R. Estimating the true global burden of mental illness. Lancet Psychiatry. 2016. https://doi. org/10.1016/S2215-0366(15)00505-2.

9. Jourdan D, Christensen JH, Darlington E, Bonde AH, Bloch $\mathrm{P}$, Jensen BB, Bentsen P. The involvement of young people in school-and community-based noncommunicable disease prevention interventions: a scoping review of designs and outcomes. BMC Public Health. 2016. https://doi.org/10.1186/s1288 9-016-3779-1.

10. Nutbeam D, Clarkson J, Phillips K, Everett V, Hill A, Catford J. The health-promoting school: organisation and policy development in Welsh secondary schools. Health Educ J. 1987;46(3):109-15.

11. Peters LWH, Kok G, Ten Dam GT, Buijs GJ, Paulussen TG. Effective elements of school health promotion across behavioral domains: a systematic review of reviews. BMC Public Health. 2009. https://doi.org/10.1186/1471-2458-9-182.

12. WHO Regional Office for the Western Pacific. Health-promoting schools series 5: regional guidelines. Development of healthpromoting schools - a framework for action. WHO/WPRO; 1996.

13. Marshall BJ, Sheehan MM, Northfield JR, Maher S, Carlisle R, Leger LH. School-based health promotion across Australia. J Sch Health. 2000;70(6):251-2.

14. St Leger L, Nutbeam D. Research into health promoting schools. J School Health. 2000;70(6):257-9.

15. Moon AM, Mullee MA, Rogers L, Thompson RL, Speller V, Roderick P. Helping schools to become health-promoting environments - an evaluation of the Wessex Healthy Schools Award. Health Promot Int. 1999;14(2):111-22.

16. Lee A, Cheng F, Yuen H, Ho M, Lo A, Fung Y, Leung T. Achieving good standards in health promoting schools: preliminary analysis one year after the implementation of the Hong Kong Healthy Schools Award scheme. Public Health. 2007;121(10):752-60.

17. Lee A, St Leger L, Cheng F, Hong Kong Healthy School Team. The status of health-promoting schools in Hong Kong and implications for further development. Health Promot Int. 2007;22(4):316-26

18. Heesch KC, Hepple E, Dingle K, Freeman N. Establishing and implementing a health promoting school in rural Cambodia. Health Promot Int. 2018. https://doi.org/10.1093/heapro/day114. 
19. World Health Organization. Introduction to Global Accelerated Action for the Health of Adolescents (AA-HA!): Guidance to Support Country Implementation. 2017. https://www.who.int/mater nal_child_adolescent/topics/adolescence/framework-accelerate d-action/background/en/. Accessed 1 June 2019.

20. Lee A. Helping schools to promote healthy educational environments as new initiatives for school based management: the Hong Kong Healthy Schools Award Scheme. Promot Educ. 2002;9(1_ suppl):29-32 (Renamed as Global Health Promotion).

21. Lee A, Cheng FF, Fung Y, St Leger L. Can Health Promoting Schools contribute to the better health and wellbeing of young people? The Hong Kong experience. J Epidemiol Community Health. 2006;60(6):530-6.

22. Lee A, Wong MCS, Keung VMW, Yuen HSK, Cheng F, Mok JSY. Can the concept of Health Promoting Schools help to improve students' health knowledge and practices to combat the challenge of communicable diseases: case study in Hong Kong? BMC Public Health. 2008;8(1):42.

23. Lee A, Keung V, Lo A, Kwong A. Healthy School environment to tackle youth mental health crisis. Hong Kong J Paediatr. 2016;21(2):134-5.

24. Joyce A, Dabrowski A, Aston R, Carey G. Evaluating for impact: what type of data can assist a health promoting school approach? Health Promot Int. 2017;32(2):403-10.

25. Moynihan S, Jourdan D, Mannix McNamara P. An examination of health promoting schools in Ireland. Health Educ. 2016;116(1):16-33.

26. Macnab AJ, Gagnon FA, Stewart D. Health promoting schools: consensus, strategies, and potential. Health Educ. 2014;114(3):170-85.

27. Macnab AJ, Stewart D, Gagnon FA. Health promoting schools: initiatives in Africa. Health Educ. 2014;114(4):246-59.

28. St Leger L, Young IM. Creating the document 'Promoting health in schools: from evidence to action'. Glob Health Promot. 2009;16(4):69-71.

29. Langford R, Bonell CP, Jones HE, Pouliou T, Murphy SM, Waters E, Komro KA, Gibbs LF, Magnus D, Campbell R. The WHO Health Promoting School framework for improving the health and well-being of students and their academic achievement. Cochrane Database systematic Rev. 2014;4:CD008958.

30. Inchley J, Muldoon J, Currie C. Becoming a health promoting school: evaluating the process of effective implementation in Scotland. Health Promot Int. 2006;22(1):65-71.

31. Rowling L. Strengthening, "school" in school mental health promotion. Health Educ. 2009;109(4):357-68.

32. Turunen H, Sormunen M, Jourdan D, Von Seelen J, Buijs G. Health promoting schools-a complex approach and a major means to health improvement. Health Promot Int. 2017;32(2):177-84.

33. Bustreo F, Chestnov O. Emerging issues in adolescent health and the positions and priorities of the world health organization. J Adolesc Health. 2013;52:S4.

34. Blum R, Dick B. Strengthening global programs and policies for youth based on the emerging science. J Adolesc Health. 2013;52(2):S1-3.

35. Spear LP. Adolescent neurodevelopment. J Adolesc Health. 2013;52(2):S7-13.

36. Potenza MN. Biological contributions to addictions in adolescents and adults: prevention, treatment, and policy implication. J Adolesc Health. 2013;52:S22-32.

37. Macnab A. The Stellenbosch consensus statement on health promoting schools. Glob Health Promot. 2013;20(1):78-81.

38. Moon AM, Mullee MA, Rogers L, Thompson RL, Speller V, Roderick Moon AM, Mullee MA, Thompson RL, Speller V, Roderick P. Health-related research and evaluation in schools. Health Educ. 1999;99(1):27-34.
39. Lee A, Lo ASC, Keung MW, Kwong CM, Wong KK. Effective Health Promoting School for better health of children and adolescents: indicators for success. BMC Public Health. 2019;19:1088. https://doi.org/10.1186/s12889-019-7425-6.

40. Chen FL, Lee A. Health-promoting educational settings in Taiwan: development and evaluation of the Health-Promoting School Accreditation System. Glob Health Promot. 2016;23(1_suppl):18-25.

41. Peters MD, Godfrey CM, Khalil H, McInerney P, Parker D, Soares CB. Guidance for conducting systematic scoping reviews. Int J Evid Based Healthc. 2015;13(3):141-6.

42. Tricco AC, Lillie E, Zarin W, O'Brien K, Colquhoun H, Kastner M, Levac D, Ng C, Sharpe JP, Wilson K, Kenny M. A scoping review on the conduct and reporting of scoping reviews. BMC Med Res Methodol. 2016;16(1):15.

43. McIsaac JLD, Mumtaz Z, Veugelers PJ, Kirk SF. Providing context to the implementation of health promoting schools: a case study. Eval Progr Plan. 2015;53:65-71.

44. Moher D, Liberati A, Tetzlaff J, Altman DG, The PRISMA Group (2009). Preferred reporting items for systematic reviews and meta-analyses: the PRISMA statement. PLoS Med. 2009;6(7):e1000097. https://doi.org/10.1371/journ al.pmed.1000097.

45. Catalano RF, Oesterle S, Fleming CB, Hawkins JD. The importance of bonding to school for healthy development: findings from the Social Development Research Group. J Sch Health. 2004;74(7):252-61.

46. Wies R. Policy definition and classification: aspects, criteria and examples. In: Proceedings of the IFIP/IEEE international workshop on distributed systems: operation and management; 1994. pp. $10-12$.

47. Simovska V. What do health-promoting schools promote? Processes and outcomes in school health promotion. Health Educ. 2012;112(2):84-8.

48. Babazadeh T, Fathi B, Shaghaghi A, Allahverdipour H. Lessons learnt from pilot field test of a comprehensive advocacy program to support health promoting schools' project in Iran. Health Promot Perspect. 2017;7(1):14.

49. Shahhosseini Z, Hamzehgardeshi Z. Female adolescents' perspective about reproductive health education needs: a mixed methods study with explanatory sequential design. Int J Adolesc Med Health. 2015;27(1):57-63.

50. FRESH M\&E Coordinating Group. Monitoring and Evaluation Guidance for School Health Programs. FRESH M\&E Coordinating Group. 2014. https://hivhealthclearinghouse.unesco.org/sites/ default/files/resources/FRESH_M\&E_CORE_INDICATORS.pdf. Accessed 30 Aug 2019.

51. Lee A, Cheung MB. School as setting to create a healthy learning environment for teaching and learning using the model of health promoting school to foster school-health partnership. J Profess Capac Community. 2017;2(4):200-14. https://doi.org/10.1108/ JPCC-05-2017-0013.

52. World Health Organization. Health Promoting School: experiences from the Western Pacific Region. Geneva: World Health Organization. 2017. http://iris.wpro.who.int/bitstream/handl e/10665.1/13551/9789290617884-eng.pdf. Accessed 30 Aug 2019.

53. International Union for Health Promotion and Education (IUHPE). Achieving Health Promoting Schools: Guidelines for promoting health in schools. IUHPE. 2009. https://www.iuhpe.org/images/ PUBLICATIONS/THEMATIC/SCHOOL/FacilitatingDialogue HE_EN.pdf. Accessed 31 Aug 2019.

54. IUHPE. Promoting health in school: From evidence to action. IUHPE. 2010. https://www.iuhpe.org/images/PUBLICATIONS/ THEMATIC/HPS/Evidence-Action_ENG.pdf. Accessed 31 Aug 2019. 
55. ASCD. Whole School, Whole Community, Whole Child (WSCC). A collaborative approach to learning and health. ASCD. 2014. http://www.ascd.org/ASCD/pdf/siteASCD/publications/whole child/wscc-a-collaborative-approach.pdf. Accessed 31 Aug 2019.

56. IUHPE. Facilitating Dialogue between the Health and Education Sectors to advance School Health Promotion and Education. IUHPE. 2012. https://www.iuhpe.org/images/PUBLICATIONS/ THEMATIC/HPS/Evidence-Action_ENG.pdf. Accessed 31 Aug 2019.

57. Safarjan E, Buijis G, de Ruiter S. School action planner: A companion document for the SHE online school manual. SHE. 2013. http://www.schoolsforhealth.eu/for-schools/. Accessed 31 Aug 2019.

58. Global Partnership for Education and World Bank Group. School Health Integrated Programming (SHIP) Extension: final report. Global Partnership for Education and World Bank Group. 2018. https://www.globalpartnership.org/content/school-health-integ rated-programming-ship-extension. Accessed 31 Aug 2019.

59. Barnekow V, Buijs G, Clift S, Jensen BB, Paulus P, Rivett, D, Young I. Health-promoting schools: a resource for developing indicators. International Planning Committee, European Network of Health Promoting Schools; 2006.

60. Kam CM, Greenberg MT, Walls CT. Examining the role of implementation quality in school-based prevention using the PATHS curriculum. Prev Sci. 2003;4(1):55-63.

61. Stewart-Brown S. What is the evidence on school health promotion in improving health or preventing disease and, specifically, what is the effectiveness of the Health Promoting Schools approach? Geneva: World Health Organization. 2006. http://www. euro.who.int/_data/assets/pdf_file/0007/74653/E88185.pdf. Accessed 31 Aug 2019.

62. Weare K, Markham W. What do we know about promoting mental health through schools?. Promot Educ. 2005;12(3-4):118-22 (renamed as Global Health Promotion).

63. West P. School effects research provide new and stronger evidence in support of the health-promoting school idea. Health Educ. 2006;106(6):421-4.

64. Hoyle TB, Samek BB, Valois RF. Building capacity for the continuous improvement of health-promoting schools. J Sch Health. 2008;78(1):1-8.

65. Lee A, Lo A. Keung V, Kwong A. Healthy school policies. Theory and practice of health promoting school: getting started. Hong Kong: Centre for Health Education and Health Promotion, The Chinese University of Hong Kong, 2018.

66. Saewyc DM. School health services: fulfilling the promise for prevention: background document for a global expert consultation. Geneva: WHO Maternal Neonatal Child and Adolescent Health Branch; 2017.

67. Bellomo AJ. Emergency management. In: Frumkin H, Geller RJ, Rubin IL, Nodvin J, editors. Safe and healthy school environments. New York: Oxford University Press; 2006. p. 270-94.

68. Phaitrakoon J, Powwattana A, Lagampan S, Klaewkla J. The diamond level health promoting schools (DLHPS) program for reduced child obesity in Thailand: lessons learned from interviews and focus groups. Asia Pac J Clin Nutr. 2014;23(2):293-300.

69. UNESCO. UNESCO Strategy on Education for Health and Well-being: Contributing to the sustainable development goals. UNESCO. 2016. https://hivhealthclearinghouse.unesco.org/sites/ default/files/resources/FRESH_M\&E_CORE_INDICATORS.pdf. Accessed 31 Aug 2019.

70. Cohen DA, Scribner RA, Farley TA. A structural model of health behavior: a pragmatic approach to explain and influence health behaviors at the population level. Prev Med. 2000;30(2):146-54.

71. Gordon J, Turner K. School staff as exemplars-where is the potential? Health Educ. 2001;101(6):283-91.
72. Ministry of Education, Denmark. The Folkeskole (Consolidation) Act, Consolidation Act No. 730 of 21 July 2000 as amended by section 64 of Act No. 145 of 25 March 2002, section 2 of Act No. 274 of 8 May 2002, section 1 of Act No. 412 of 6 June 2002, section 54 of Act No. 1050 of 17 December 2002, section 8 of Act No. 297 of 30 April 2003, section 1 of Act No. 299 of 30 April 2003 and by Act No. 300 of 30 April 2003. Copenhagen: Ministry of Education. 2003. http://eng.uvm.dk/publications/laws/folke skole.htm?menuid $=2010$.

73. Brown KM, Elliott SJ, Robertson-Wilson J, Vine MM, Leatherdale ST. Can knowledge exchange support the implementation of a health-promoting schools approach? Perceived outcomes of knowledge exchange in the COMPASS study. BMC Public Health. 2018;18(1):351.

74. Resnick MD, Harris LJ, Blum RW. The impact of caring and connectedness on adolescent health and well-being. J Paediatr Child Health. 1993;29:S3-9.

75. Blum RW, McNeely CA, Rinehart PM. Improving the odds: the untapped power of schools to improve the health of teens. U.S.A: Center for Adolescent Health and Development, University of Minnesota; 2002.

76. Duckett P, Kagan C, Sixsmith J. Consultation and participation with children in healthy schools: choice, conflict and context. Am J Community Psychol. 2010;46(1-2):167-78.

77. Nyberg G, Sundblom E, Norman A, Elinder LS. A healthy school start-Parental support to promote healthy dietary habits and physical activity in children: design and evaluation of a cluster-randomised intervention. BMC Public Health. 2011;11(1): 185.

78. St Leger LH. The opportunities and effectiveness of the health promoting primary school in improving child health-a review of the claims and evidence. Health Educ Res. 1999;14(1):51-69.

79. Simovska V. Student participation: a democratic education perspective-experience from the health-promoting schools in Macedonia. Health Educ Res. 2004;19(2):198-207.

80. World Health Organization. European framework for quality standards in school health services and competencies for school health professionals. World Health Organization. 2014. http:// www.euro.who.int/_data/assets/pdf_file/0003/246981/Europeanframework-for-quality-standards-in-school-health-services-andcompetences-for-school-health-professionals.pdf?ua $=1$. Accessed 31 Aug 2019.

81. Speller V, Byrne J, Dewhirst S, Almond P, Mohebati L, Norman M, Polack S, Memon A, Grace M, Margetts B, Roderick P. Developing trainee school teachers' expertise as health promoters. Health Educ. 2010;110(6):490-507.

82. Gugglberger L. Support for health promoting schools: a typology of supporting strategies in Austrian provinces. Health Promot Int. 2011;26(4):447-56.

83. Rajaraman D, Travasso S, Chatterjee A, Bhat B, Andrew G, Parab S, Patel V. The acceptability, feasibility and impact of a lay health counsellor delivered health promoting schools programme in India: a case study evaluation. BMC Health Serv Res. 2012;12(1):127.

84. Khatib IM, Hijazi SS. Adaptation of the school health index to assess the healthy school environment in Jordan. East Mediterr Health J. 2011;17(1):62-8.

85. Nkamba EM, Tilford S, Williams SA. Components of Health Promoting Schools in Ugandan primary schools: a pilot study. Int $\mathrm{J}$ Health Promot Educ. 2008;46(3):84-93.

86. Himmelman AT. Collaboration for a change. Definitions, models, roles and a guide for collaborative process. Minneapolis: Hubert Humphrey Institute of Public Affairs, University of Minnesota. 2002.

87. Adamowitsch M, Gugglberger L, Dür W. Implementation practices in school health promotion: findings from an Austrian multiple-case study. Health Promot Int. 2017;32(2):218-30. 
88. Kann L, Kinchen SA, Williams BI, Ross JG, Lowry R, Grunbaum JA, Kolbe LJ. Youth risk behavior surveillance-United States, 1999. J Sch Health. 2000;70(7):271-85.

89. Lee A, Keung VM, Lo AS, Kwong AC, Armstrong ES. Framework for evaluating efficacy in health promoting schools. Health Educ. 2014;114(3):225-42.

90. Kessler RC, Green JG, Gruber MJ, Sampson NA, Bromet E, Cuitan M, Furukawa TA, Gureje O, Hinkov H, Hu CY, Lara C. Screening for serious mental illness in the general population with the K6 screening scale: results from the WHO World Mental Health (WMH) survey initiative. Int J Methods Psychiatr Res. 2010;19(S1):4-22.

91. Huebner ES, Seligson JL, Valois RF, Suldo SM. A review of the brief multidimensional students' life satisfaction scale. Soc Indic Res. 2006;79(3):477-84.

92. Lee A. Health Promoting Schools: evidence for a holistic approach in promoting health and improvement of health literacy. Appl Health Econ Health Policy. 2009;7(1):11-7.
93. National Academy of Medicine. CONCEPT NOTE: Forum on Investing in Young Children Globally. An activity of the Board on Children, Youth, and Families and Board on Global Health at Institute of Medicine and National Research Council of The National Academy of Sciences. Washington, DC. The National Academy of Medicine, 2017. http://nationalacademies.org/hmd/ / media/Files/Activity\%20Files/Children/iYCG/iYCG\%20Con cept\%20Paper.pdf. Accessed 2 Sep 2019.

94. Molina H. Integrated and Co-ordinated Programme in Chile. iYCG Workshop. Institute of Medicine, Centre for Health Education and Health Promotion and Wu Yee Sun College of the Chinese University of Hong Kong. March 14-15, 2015, Hong Kong. In National Academies of Science, Engineering and Medicine (2015). Using existing platforms to integrate and co-ordinate investments for children: Summary of a joint workshop. Chapter 3: A collaborative Multiplier Approach To Early Childhood Development. Washington, DC. The National Academic Press, 2015. https://doi.org/10.17226/23637. 